\title{
ANALISIS INFORMASI CITRA ANATOMI ANTARA PENGGUNAAN APLIKASI CONSTANCE LEVEL APPEARANCE (CLEAR) DAN NON CLEAR PADA PEMERIKSAAN MRI CERVICAL IRISAN SAGITAL T2WI FSE KASUS HNP
}

\section{ANALYSIS OF ANATOMICAL IMAGE INFORMATION BETWEEN USING A CONSTANCE LEVEL APPEARANCE (CLEAR) APLICATION AND WITHOUT A CLEAR APLICATION ON CERVICAL MRI EXAMINATION WITH T2WI FSE SAGITAL HNP CASE}

\author{
Dea Febri Mardiyanti ${ }^{1)}$, Sugiyanto $^{2)}$, Yeti Kartikasari ${ }^{3)}$ \\ ${ }^{1)}$ Ciputra Hospital, Jakarta \\ ${ }^{2,3)}$ Health Polytechnics of Semarang-Indonesia \\ e-mail : deamardiyanti0202@gmail.com
}

\begin{abstract}
Background: This study aims to determine the anatomical image information between using CLEAR aplication and without CLEAR (Non CLEAR) aplication on cervical MRI examination with T2WI FSE sagital HNP case and to determine which is the best image between using CLEAR aplication and Non CLEAR aplication on cervical MRI examination with T2WI FSE sagital HNP case.

Methods: This research was a quantitative research with an experimental approach Subjects of this study were eight patients in Siloam Lippo Village Hospital. Images resulted was assessed by radiology physician using questionnairs. Data were analyzed using Wilcoxon test to determine differences of image information and using mean rank test to determine the best image between using CLEAR application and without CLEAR aplication.

Results: This study showed that there were differences anatomical image information between using CLEAR application and without CLEAR aplication on cervical MRI examination with T2WI FSE sagital HNP case, with $p=0,000(p$ value $<0,05)$. Cervical MRI examination with CLEAR aplication T2WI FSE produced the best image with the sum of the rank was 300,00 on the negative rank which showed that the image information without CLEAR aplication T2WI FSE lower than image information with CLEAR aplication T2WI FSE.

Conclusion: There were differences the anatomical image information between using CLEAR application and without CLEAR aplication on cervical MRI examination with T2WI FSE sagital HNP case.
\end{abstract}

Keywords: cervical MRI examination, CLEAR aplication, without CLEAR aplication, T2WI FSE sagital

\section{PENDAHULUAN}

Magnetic Resonance Imaging (MRI) merupakan suatu teknik penggambaran penampang tubuh berdasarkan prinsip resonansi magnetik inti atom hidrogen. Kelebihan MRI salah satunya dapat membantu mengevaluasi kondisi seperti infeksi tulang, kelainan pada tulang belakang, tumor pada tulang dan jaringan lunak, serta peradangan sendi. MRI juga dapat mengetahui kondisi abnormal pada sendi yang disebabkan cedera traumatis atau berulang. Pemeriksaan MRI pada tulang belakang salah satunya digunakan pada vertebra cervical.

Umumnya pemeriksaan MRI vertebra cervical menggunakan pembobotan T1 dan T2 dengan sekuens Spin Echo atau Fast Spin Echo. Pada pemeriksaan MRI vertebra cervical pembobotan T2 FSE potongan axial dan sagital memberikan lebih banyak informasi diagnostik karena Signal to Noise Ratio (SNR) yang lebih tinggi (Reiser, 2007).

Pada pemeriksaan MRI vertebra cervical menggunakan radio frekuensi (RF) koil berupa surface coil yang berfungsi sebagai penerima gelombang frekuensi radio yang digunakan dalam scanner MRI. Koil RF adalah salah satu komponen yang paling penting yang mempengaruhi kualitas gambar. Menurut kuperman (2000), surface coil memiliki tingkat kehomogenitasan koil yang paling jelek dibanding koil volume. Koil volume memiliki Intensity Inhomogeinity (IIH) yang bagus tetapi miskin SNR, sedangkan surface coil memiliki SNR yang baik tetapi Intensity Inhomogeinity (IIH) tidak bagus (Uros Vovk, et al, 2007). IIH akan menurunkan kualitas citra yang dihasilkan karena merupakan salah satu jenis artefak. IIH terjadi karena jaringan tertentu direpresentasikan dengan distribusi nilai intensitas yang tidak sama. IIH disebabkan oleh inhomogenitas pada medan magnet statis, variasi sensitivitas koil penerima RF, optimasi pulsa sekuen dan pergerakkan pasien (Thord Andersson, et al, 2014).

Pada pesawat MRI Philips koreksi IIH menggunakan metode prospektif multikoil, metodenya dinamakan sebagai Constance Level Appearance (CLEAR). Penggunaan aplikasi CLEAR pada MRI Cervical T2WI FSE diharapkan akan 
menghasilkan citra diagnostik dengan informasi anatomi yang jelas tanpa adanya artefak intensity inhomogeinity.

\section{METODE}

Jenis penelitian ini adalah penelitian kuantitatif dengan pendekatan eksperimen. Sampel penelitian adalah delapan pasien MRI Cervical T2WI FSE irisan sagital dengan klinis HNP. Setiap pasien dilakukan scanning dua kali pada T2WI FSE irisan sagital, scan pertama tanpa mengaktifkan CLEAR dan scan kedua dengan mengaktifkan CLEAR pada T2WI FSE irisan sagital. Citra yang yang telah didapat kemudian dinilai dengan mengisikan skor 1-3 pada lembar kuesioner yang berisi tentang anatomi MRI cervical oleh tiga responden dalam hal ini adalah dokter spesialis radiologi yang telah berpengalaman dalam expertise citra MRI. Untuk menentukan apakah ada perbedaan informasi citra anatomi MRI cervical T2WI FSE CLEAR dan NON CLEAR pada irisan sagital dilakukan uji statistik Wilcoxon. Alasan dilakukan pengujian dengan Wilcoxon karena data tersebut merupakan dua kelompok sampel yang berpasangan dengan jenis data ordinal. Sedangkan untuk mengetahui citra terbaik antara MRI cervical T2WI FSE CLEAR dan tanpa CLEAR dapat dilihat dari nilai mean rank.

Tahap pertama proses scanning adalah Survey/localizer irisan axial, coronal, sagittal, kemudian tahap kedua Scanning T2WI FSE irisan sagital tanpa CLEAR. Selanjutnya tahap ketiga Referensi scan dengan memilih "refscan for spine coil" dari examcard, dan yang terakhir adalah Scanning T2WI FSE irisan sagital dengan mengaktifkan CLEAR. Variabel terkontrol : TR 2620 ms, TE 100 ms, NSA 6, Slice thickness $12 \mathrm{~mm}$, Window Width 2180 dan Window Level 668.

Pada Analisis statistik ini ditetapkan tingkat kepercayaan (level of significance) dengan nilai $\mathrm{p}=0,05$. Ho ditolak apabila $p$ value $<0,05$, yang berarti ada perbedaan informasi citra anatomi antara penggunaan aplikasi CLEAR dan Non CLEAR pada pemeriksaan MRI Vertebra Cervical pada irisan Sagital T2WI FSE dengan kasus HNP. H0 diterima apabila $p$ value > 0,05 , yang berarti tidak ada perbedaan informasi citra anatomi antara penggunaan aplikasi CLEAR dan Non CLEAR pada pemeriksaan MRI Vertebra Cervical pada irisan Sagital T2WI FSE dengan kasus HNP.

\section{HASIL}

Penelitian perbedaan informasi citra anatomi antara penggunaan aplikasi CLEAR dan Non CLEAR pada pemeriksaan MRI Cervical irisan sagital T2WI FSE pada kasus HNP yang dilakukan di Instalasi Radiologi Siloam Hospital Lippo Village mengambil sampel 16 citra yang terdiri dari 8 pasien, dimana 1 orang pasien diberikan 2 perlakuan, yaitu mengunakan aplikasi CLEAR dan tanpa menggunakan aplikasi CLEAR (Non CLEAR) pada T2WI FSE irisan sagital. Pada delapan pasien tersebut didiagnosa mengalami HNP cervicalis. Karakteristik pasien terdiri dari 2 orang wanita dan 6 orang pria dengan usia antara $40-71$ tahun dan berat badan rata-rata pasien $67 \mathrm{~kg}$.

Hasil uji beda wilcoxon pada masing-masing organ MRI T2WI FSE CLEAR dan T2WI FSE Non CLEAR
Tabel 1. Hasil uji beda wilcoxon pada masing-masing organ MRI T2WI FSE CLEAR dan T2WI FSE Non CLEAR

\begin{tabular}{|c|c|c|c|}
\hline No & Organ & Nilai & Makna \\
\hline 1. & Spinal Cord & 1,00 & $\begin{array}{l}\text { Nilai p>0,05 (tidak ada } \\
\text { perbedaan yang bermakna } \\
\text { antara citra spinal cord T2WI } \\
\text { FSE CLEAR dan T2WI FSE } \\
\text { Non CLEAR) }\end{array}$ \\
\hline 2. & $P L L$ & 1,00 & $\begin{array}{l}\text { Nilai p>0,05 (tidak ada } \\
\text { perbedaan yang bermakna } \\
\text { antara citra } P L L \text { T2WI FSE } \\
\text { CLEAR dan T2WI FSE Non } \\
\text { CLEAR) }\end{array}$ \\
\hline 3. & Nerve Roots & 0,001 & $\begin{array}{l}\text { Nilai } p<0,05 \text { (ada perbedaan } \\
\text { yang bermakna antara citra } \\
\text { nerve roots T2WI FSE CLEAR } \\
\text { dan T2WI FSE Non CLEAR) }\end{array}$ \\
\hline 4. & $C S F$ & 1,00 & $\begin{array}{l}\text { Nilai p>0,05 (tidak ada } \\
\text { perbedaan yang bermakna } \\
\text { antara citra } C S F \text { T2WI FSE } \\
\text { CLEAR dan T2WI FSE Non } \\
\text { CLEAR) }\end{array}$ \\
\hline 5. & $\begin{array}{l}\text { Neural } \\
\text { Foramen }\end{array}$ & 0,157 & $\begin{array}{l}\text { Nilai p>0,05 (tidak ada } \\
\text { perbedaan yang bermakna } \\
\text { antara citra neural formaen } \\
\text { T2WI FSE CLEAR dan T2WI } \\
\text { FSE Non CLEAR) }\end{array}$ \\
\hline 6. & Lig. Flavum & 0,317 & $\begin{array}{l}\text { Nilai p>0,05 (tidak ada } \\
\text { perbedaan yang bermakna } \\
\text { antara citra ligamentum flavum } \\
\text { T2WI FSE CLEAR dan T2WI } \\
\text { FSE Non CLEAR) }\end{array}$ \\
\hline 7. & $\begin{array}{l}\text { Corpus } \\
\text { Vertebrae }\end{array}$ & 0,003 & $\begin{array}{l}\text { Nilai } \mathrm{p}<0,05 \text { (ada perbedaan } \\
\text { yang bermakna antara citra } \\
\text { corpus vertebrae T2WI FSE } \\
\text { CLEAR dan T2WI FSE Non } \\
\text { CLEAR) }\end{array}$ \\
\hline 8. & Discus & 0,000 & $\begin{array}{l}\text { Nilai } \mathrm{p}<0,05 \text { (ada perbedaan } \\
\text { yang bermakna antara citra } \\
\text { discus T2WI FSE CLEAR dan } \\
\text { T2WI FSE Non CLEAR) }\end{array}$ \\
\hline 9. & Facet Joint & 0,000 & $\begin{array}{l}\text { Nilai } \mathrm{p}<0,05 \text { (ada perbedaan } \\
\text { yang bermakna antara citra } \\
\text { facet joint T2WI FSE CLEAR } \\
\text { dan T2WI FSE Non CLEAR) }\end{array}$ \\
\hline
\end{tabular}

Setelah dilakukan uji beda wilcoxon pada masing masing organ, kemudian dilakukan uji beda secara keseluruhan untuk menjawab hipotesis penelitian yang telah ditetapkan.

\begin{tabular}{cc} 
Tabel 2. Hasil uji beda Wilcoxon secara keseluruhan \\
\hline & $\begin{array}{c}\text { Informasi citra anatomi T2WI } \\
\text { FSE Non CLEAR - T2WI FSE } \\
\text { CLEAR }\end{array}$ \\
\hline Nilai $\mathrm{p}(p$ value $)$ & 0,000 \\
\hline
\end{tabular}

Pada data tabel 2 menyatakan bahwa ada perbedaan bermakna antara informasi citra anatomi T2WI FSE 
CLEAR dan T2WI FSE Non CLEAR dengan nilai $\mathrm{p}=$ 0,000 (nilai $\mathrm{p}<0,05$ ) sehinggan Ho diolak dan Ha diterima.

Tabel 3. Hasil jumlah ranking (sum of rank)

\begin{tabular}{ccccc}
\hline & & $\mathrm{N}$ & $\begin{array}{c}\text { Rata- } \\
\text { rata } \\
\text { ranking }\end{array}$ & $\begin{array}{c}\text { Jumlah } \\
\text { Ranking }\end{array}$ \\
\hline Informasi citra & $\begin{array}{c}\text { Ranking } \\
\text { Neg. }\end{array}$ & 24 & 12.50 & 300.00 \\
MRI Cervical & $\begin{array}{c}\text { Ranking } \\
\text { T2WI Non }\end{array}$ & 0 & .00 & .00 \\
$\begin{array}{c}\text { CLEAR - } \\
\text { Pos. }\end{array}$ & Ties & 0 & & \\
MRI Cervical & Total & 24 & & \\
T2WI CLEAR & T2Wasi citra & & & \\
\hline
\end{tabular}

Pada data tabel 3 menunjukkan bahwa citra terbaik adalah T2WI FSE CLEAR pada pemeriksaan MRI Cervical T2WI FSE dengan jumlah ranking sebesar 300,00 pada ranking negatif.
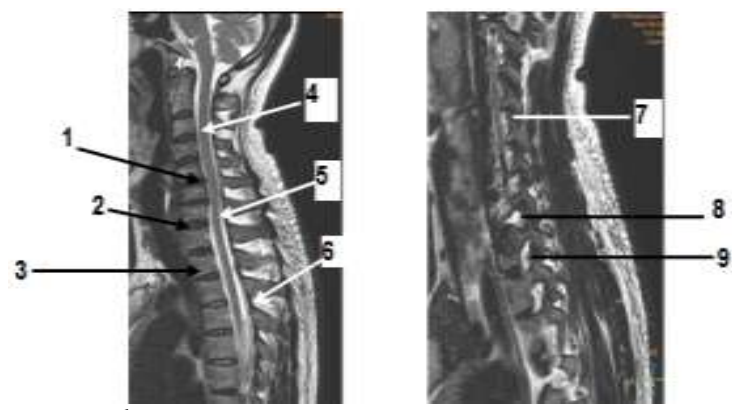

Keterangan gambar :

1. Posterior Longitudinal Ligamentum (PLL)

2. Discus

3. Corpus vertebrae

4. Spinal cord

5. CSF

6. Ligamentum flavum

7. Facet joint

8. Neural foramen

9. Nerve roots

Gambar 1. Radiograf citra MRI Cervical T2WI FSE CLEAR

\section{DISKUSI}

Perbedaan informasi citra anatomi informasi citra anatomi antara penggunaan aplikasi CLEAR dan Non CLEAR pada pemeriksaan MRI Cervical irisan sagital T2WI FSE pada Kasus HNP.

Berdasarkan hasil uji beda wilcoxon menyatakan bahwa ada perbedaan yang bermakna untuk organ nerve roots, facet joint, discus, dan corpus vertebrae pada T2WI FSE pemeriksaan MRI Cervical irisan sagital dengan menggunakan aplikasi CLEAR dan tanpa Aplikasi CLEAR (Non CLEAR), dengan nilai kemaknaan ( $\mathrm{p}$ value) pada organ nerve roots 0,0001 ; facet joint 0,000 ; discus 0,000 ; corpus vertebrae 0,000. Sedangkan pada organ spinal cord, posterior longitudinal ligamentum, CSF, ligamentum flavum dan neural foramen tidak ada perbedaan yang bermakna dengan nilai kemaknaan ( $\mathrm{p}$ value) 1, 000 untuk organ spinal cord, posterior longitudinal ligamentum, dan CSF; 0, 157 untuk organ neural foramen; 0,317 untuk organ ligamentum flavum.

Pada uji beda wilcoxon informasi citra anatomi secara keseluruhan menyatakan bahwa ada perbedaan yang bermakna pada informasi citra anatomi secara keseluruhan dengan nilai $\mathrm{p} 0,000(\mathrm{p}<0,05)$ pada T2WI FSE pemeriksaan MRI Cervical irisan sagital dengan menggunakan aplikasi CLEAR dan tanpa Aplikasi CLEAR (Non CLEAR).

Perbedaan tersebut disebabkan karena penggunaan suatu aplikasi yang diterapkan dalam pencitraan MRI menggunakan koil permukaan yang akan mempengaruhi informasi citra yang dihasilkan. Dalam penelitian ini menggunakan aplikasi Contance Level Appearance (CLEAR) sebagai metode koreksi sinyal dalam penggunaan surface coil dalam hal ini pada pemeriksaan MRI cervical, T2WI FSE irisan sagital. T2WI FSE CLEAR dan Non CLEAR memiliki kelebihan dan kekurangan masing-masing.
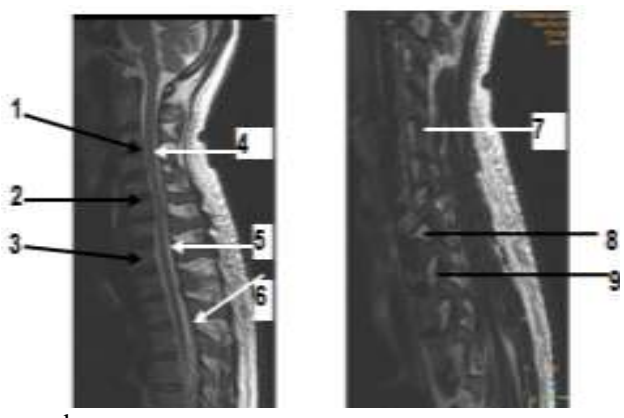

Keterangan gambar:

1. Posterior Longitudinal Ligamentum (PLL)

2. Discus

3. Corpus vertebrae

4. Spinal cord

5. CSF

6. Ligamentum flavum

7. Facet joint

8. Neural foramen

9. Nerve roots

Gambar 2. Radiograf citra MRI Cervical T2WI FSE tanpa CLEAR

Pada T2WI FSE CLEAR memiliki kontras yang lebih tinggi dengan inhomogeinity yang rendah dibanding dengan T2WI FSE tanpa aplikasi CLEAR. Akan tetapi waktu yang dibutuhkan lebih lama daripada T2WI tanpa aplikasi CLEAR, yaitu 6 menit 3 detik sedangkan pada T2WI Non CLEAR hanya membutuhkan waktu 5 menit 48 detik. Pada T2WI CLEAR membutuhkan RefScan untuk mengkalkulasi konstribusi sinyal yang diterima oleh koil pearmukaan yang selanjutnya akan dikoreksi oleh aplikasi CLEAR.

Hal ini sesuai dengan Dar-Yeoung Chen (2015) bahwa koil permukaan hanya sensitif pada sinyal yang dihasilkan dari daerah yang dekat dengan koil dan secara bertahap sinyal yang dihasilkan akan menurun dampaknya akan menyebabkan homogenitas sinyal pada organ yang dimaksud akan berkurang, sehingga perlu suatu metode koreksi untuk menjaga agar sinyal yang diterima tetap homogen. Pada pesawat MRI banyak metode koreksi yang diterapkan untuk mengatasi inhomogeinity, salah satunya adalah penggunaan aplikasi CLEAR yang diterapkan pada surface coil pesawat 
MRI Philips. Contance Level Appearance (CLEAR) menggunakan metode multikoil yang memiliki keuntungan menghasilkan citra dengan SNR yang tinggi dengan inhomogeinity yang rendah karena metodenya menggabungkan citra dari koil permukaan dan koil volume sehingga mampu memperlihatkan adanya perbedaan kontras gambar antara organ dan jaringan sekitarnya, namun membutuhkan waktu akuisisi yang lebih lama (Uros Vovk, et al, 2007)

Informasi citra anatomi terbaik pada MRI Cervical T2WI FSE irisan sagital dengan menggunakan aplikasi CLEAR dan tanpa aplikasi CLEAR. Berdasarkan hasil uji statistik wilcoxon menyatakan bahwa jumlah rangking informasi citra anatomi keseluruhan T2WI FSE Non CLEAR lebih rendah dibandingkan dengan T2WI FSE CLEAR pada MRI cervical irisan sagital, yakni sebesar 300,00. Hal ini didukung nilai prosentase dari perhitungan tabulasi silang (crosstabulation) per kriteria informasi citra. Hal ini dikarenakan penggunaan aplikasi CLEAR pada MRI Cervical T2WI FSE irisan sagital dengan menggunakan loil permukaan memberikan informasi citra yang lebih baik karena menjaga SNR dari organ yang akan dievaluasi tetap konstan dan homogen, namun membutuhkan waktu akuisisi data yang lebih lama, sedangkan penggunaan aplikasi CLEAR pada MRI Cervical T2WI FSE irisan sagital dapat diabaikan untuk mendapatkan waktu akuisisi data yang lebih cepat, namun evaluasi diagnostik hanya terbatas pada organ spinal cord, posterior longitudinal ligamentum, ligamentum flavum, dan neural foramen.

\section{SIMPULAN}

Berdasarkan hasil penelitian yang telah dilakukan menunjukan bahwa terdapat perbedaan informasi citra anatomi antara penggunaan aplikasi CLEAR dan Non CLEAR pada pemeriksaan MRI Vertebra Cervical pada irisan Sagital T2WI FSE dengan nilai $p=0,000(\mathrm{p}<0,05)$ dan citra yang mampu memberikan informasi anatomi terbaik pemeriksaan MRI Vertebra Cervical pada irisan Sagital T2WI FSE adalah T2WI FSE dengan menggunakan aplikasi CLEAR dengan nilai jumlah rangking sebesar 300,00.

\section{DAFTAR PUSTAKA}

Dar-Yeong Chen. 2015. Physics in Clinical MRI Series 5: RF Coil. https://www.linkedin.com/pulse/physics-clinical-mri-series-5-rf-coilsdar-yeong-chen, diakses pada 28 Maret 2016.

Kuperman, V. 2000. Magnetic Resonance Imaging: Physical Principles and Applications. Academic Press, San Diego, CA.

Uros Vovk, et al. 2007. A Review of Methods for Correction of Intensity Inhomogeneity in MRI. https://pdfs.semanticscholar.org $/ 5 \mathrm{eba} /$ 6400de4ed990704efac9c4fad055350dbf4d.pdf, diakses pada 28 Maret 2016.

Reiser, F. Maximillan, Semmier Wolfhard, Hricak Hedvig. 2007. Magnetic Resonance Tomography. Springer: Verlag Berlin.

Thord Andersson, et al. 2014. Consistent intensity inhomogeneity correction in water-fat MRI. http://liu.diva-portal.org/smash/get/diva2:763667 /FULLTEXT01.pdf, diakses pada 28 Maret 2016. 